\title{
Interaction between word accent and intonational boundaries in Latvian
}

\author{
José Ignacio Hualde ${ }^{1}$, Tomas Riad ${ }^{2}$ \\ ${ }^{1}$ University of Illinois at Urbana-Champaign, USA \\ ${ }^{2}$ Stockholm University, Sweden \\ jihualde@illinois.edu, tomas.riad@su.se
}

\begin{abstract}
In Latvian, primary stressed long syllables of content words bear either a level or a falling pitch contour, due to a lexical tonal accent contrast. In this paper we examine the interaction between word accents and intonational boundary tones in Latvian. We assume that intonational contours result from the combination of word-level and utterance-level tones and consider how the word accents are realized in utterances with different pragmatic values, which are in part expressed by choice of boundary tone ( $\mathrm{L} \%, \mathrm{H} \%, \mathrm{HL} \%)$. The main result of our investigation is that the existence of a lexical tonal contrast in Latvian introduces some incompatibilities between accentual melodies and intonational boundary tones (e.g. a lexical falling contour on a phrase-final syllable is incompatible with an intonational rise on the same syllable), which are resolved in different ways. Tentatively, we conclude that one resolution is to alter the tonal values of the word accents, in some instances leading to the potential positional neutralization of the contrast. Another strategy is assimilation between boundary tone and word accent. Which tone assimilates to which is left as an open question here.
\end{abstract}

Index Terms: Latvian, pitch-accent languages, intonation

\section{Introduction}

In standard Latvian, there is a lexical contrast between words with a level tone and words with a falling or non-level tone. We refer here to these tones as word accents. Surface word accent configurations are made up of both lexical and intonational tones. According to Karinšs [1], the falling accent is the marked member of a privative contrast. In this paper, however, we will remain agnostic regarding the precise nature of the contrast (privative, equipollent), but look for evidence in either direction.

The lexical tone is associated with the syllable with word stress, almost always the initial syllable of the word. The contrast can arise only where the stressed syllable is phonologically long (e.g. when the stressed syllable contains a long vowel, a diphthong or a short vowel followed by a sonorant consonant, $/ \mathrm{x} /$ or $/ \mathrm{v} /$ in coda position [2]). Historically, there was an additional lexical contrast involving glottalization in words with a falling accent. Words with glottalization were said to have "broken tone" [1]. This lexical contrast in voice quality appears to have been lost in standard Latvian [2] and glottalization is now an optional feature of words with a falling accent that enhances the two-way tonal accent distinction [3].

Other regional varieties of Latvian have undergone other mergers. In particular, in some dialects the tonal contrast has been lost whereas the glottalization feature is retained as lexically contrastive [1]. Bilingual Russian-Latvian speakers for whom Latvian is not the dominant language do not appear to make either lexical contrast [4].

In this paper we consider the interaction between tonal word accents and intonational boundary tones. We make the assumption that intonational contours result from the combination of word-level and utterance-level tones, as has been proposed in other work on languages with lexical tonal accent $[5,6]$. We expand on the analysis of Latvian in [3] by analyzing a larger dataset and by considering the contribution of lexical and pragmatic components to the intonational contours of utterances.

\section{Methods}

Four speakers of standard Latvian (3 female, 1 male) participated in this study. The speakers were from different towns in the central Latvian area: Riga, Seldus, Dundaga and Valmiera. They were recruited at Stockholm University. Participants were asked to read four sets of mini-dialogs. Each set contained fifteen mini-dialogs, all ending with sentences that are very similar across contexts, but differing in the pragmatic information that they convey.

Each of the four sets in the experimental materials that participants read includes a member of a potential tonal minimal pair. The experiment thus tests how lexical tonal contrasts are realized under different intonational conditions and, conversely, how intonational contours are affected by lexical tonal specifications. The target words that we used in the experiment are shown in Table 1. These minimal pairs are adopted from a grammar of Latvian [2]. In standard Latvian orthography, a macron is used to represent long vowels. Accentual contrasts are not indicated in the standard spelling of words. In linguistic work on Latvian, however, there are established conventions for representing word-accent using diacritics. The Level accent is represented with a tilde [ã], the Falling accent is represented with a grave accent mark [à], and the (etymological) Broken accent with a circumflex [â]. We follow these conventions here.

Table 1. Target words

\begin{tabular}{|l|l|}
\hline Level accent & Falling/Broken accent \\
\hline zāle [zã:le] 'hall’ & zāle [zâ:le] 'grass' \\
\hline stāvs [stã:vs] 'floor’ & stāvs [stà:vs] 'steep' \\
\hline
\end{tabular}

Since the two members of each of these minimal pairs are not orthographically distinguished, the materials that the participants read included English translations, so speakers knew to produce the intended word. All participants could read and speak English fluently. (One participant, L3f, only read the first of the two minimal pairs.) 
Using one of the four target words, zāle [zã:le] 'hall', to illustrate, the fifteen target sentences that were elicited are the following: (1) All new information (What happened this morning?) Pēteris teica zāle vairākas reizes 'Peter said hall several times.' (2) Contrastive focus (Did Peter say APPLE?) Nè, Pèteris teica zāle. 'No, P. said hall.' (3) Prefocal position (Did Peter say hall SLOWLY?) Nē, Pēteris teica zāle ĀTRI. 'No, P. said hall QUICKLY!' (4) Broad focus (What did Peter do?) Pèteris teica zāle. 'P. said hall.' (5) Narrow focus final (What did Peter say?) Pēteris teica zāle 'P. said hall.' (6) Narrow focus non-final (What did Peter say again?) Pèteris teica zāle vēlreiz 'P. said hall again.' (7) Obviousness statement (What did Peter say?) Pēteris teica zāle, protams. 'P. said hall, of course!' (8) Postfocus (So, Peter WROTE hall?) Nē, Pēteris TEICA zāle. 'No, P. SAID hall.' (9) Yes-no question neutral information-seeking: Vai Pēteris teica zāle? 'Did P. say hall?' (10) Confirmation-seeking yes-no question: Pèteris teica zāle, vai ne? 'P. said hall, didn't he?' (11) Surprise/Incredulity question: Vai Pèteris teica zāle? 'Did P. say hall?! (I can't believe it)' (12) Suggestion yes-no question, polite request: Vai jūs varētu pateikt zāle? 'Would you like to say hall?' (13) Command: Saki zāle! 'Say hall!' (14) Continuation: Pēteris teica zāle, Marija teica ābols, un Érika lasīja grāmatu. 'Peter said hall, Mary said apple, and Erika read a book.' (15) Whquestion: Kas ir zāle? 'What is hall?'.

In the following sections, we examine the realization of these contrasts in different contexts. Since participants were aware that they were being asked to read sentences containing accentual minimal pairs, the results of this experiment represent very careful speech, near the hyperarticulated end of the spectrum in some instances. The analysis of f0 contours was conducted in Praat [5]. Statistical analysis was performed in R [6] and RStudio [7].

\section{Results}

\subsection{Level vs. Falling/Broken accent}

From the traditional description of accentual contours we may expect words with lexical Falling/Broken accent to show a fall between the first and second mora, and words with a Level accent to display a relatively flat pitch over the stressed syllable, as in the minimal pair in Figure 1, where renditions of a minimal pair uttered by the same speaker (L2f) in the Broad focus condition have been extracted and copied one after the other.

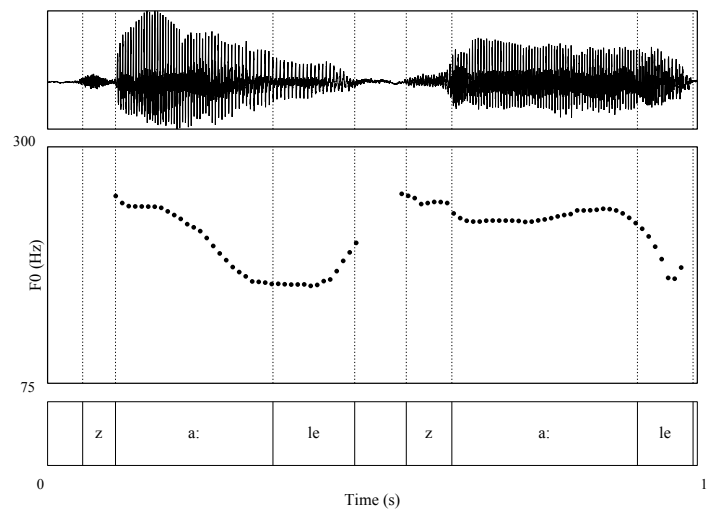

Figure 1. Minimal pair. Left: zāle [zâ:le] 'grass', Falling accent; right: zāle [zã:le] 'hall', Level accent. Broad focus condition. Speaker L2f.
Notice that although the word zāle [zâ:le] 'grass' etymologically belongs to the Broken accent class, in the lefthand example in Figure 1 there is no trace of glottalization. Other productions of the same word by the same speaker, however, show glottalization towards the end of the vowel and during the following lateral consonant. Our experimental data are in agreement with the description of the Falling vs. Broken lexical distinction having been neutralized in present-day standard Latvian. Our four speakers differed in the frequency with which they employed glottalization.

Phonologically, the Falling/Broken accent may be analyzed as an $\mathrm{H}^{*} \mathrm{~L}$ contour and the Level accent as a $\mathrm{H}^{*}$ tone over the whole bimoraic syllable nucleus. In Figure 1, both accentual melodies are followed by a L\% boundary tone, as schematized in Table 2 .

Table 2: Phonological analysis of the contours in Figure 1

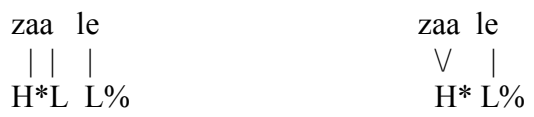

In order to establish the tonal nature of the contrast, we automatically obtained the maximum and minimum f0 values in the stressed vowel of all target words and calculated the difference. The results are shown in Figure 2 separately for each of the four speakers.

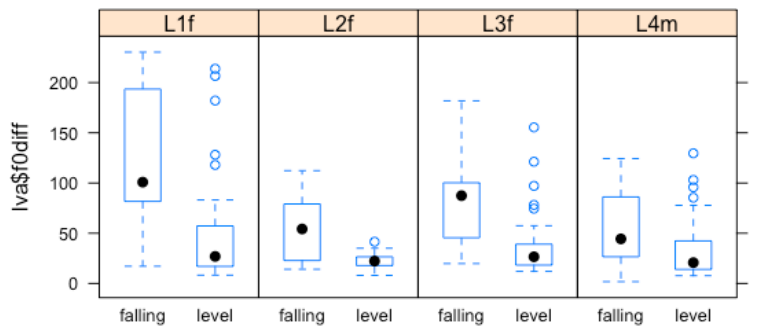

Figure 2. Difference in $f 0$ within the stressed syllable of words with lexical Falling/Broken and Level accent.

From Figure 2, it appears that words with a Falling/Broken accent do indeed tend to have a greater change in $\mathrm{f} 0$ within the stressed syllable that words with a Level accent situated in the same phrasal and discourse contexts. We performed a linear mixed effects regression analysis (function lmer_alt in the package afex [8], based on lme4 [9]), with F0 differences in the stressed vowel (centred and scaled) as dependent variable, accent type as fixed factor, and random intercepts and slopes for speaker and word pair. P-values were calculated by the Satterthwaite approximation. This analysis returns the result that accent type is significant at the $\mathrm{p}<0.05$ level $(\mathrm{t}=-3.143)$.

Another correlate of the lexical accentual contrast may be duration [3]. While all target vowels are phonologically long, those carrying a Level accent were realized as somewhat longer on average by all four of our participants. Mean values are $252.38 \mathrm{~ms}$ (sd 48.8) for words with a Falling/Broken accent vs. $302.9 \mathrm{~ms}$ (sd 50.2) for words with a Level accent. Notice, nevertheless, the rather large standard deviations. A t-test on duration by accent type returns a highly significant effect, $\mathrm{t}=$ $-7.7413, p<0.0001$. However, a linear mixed-effects regression analysis on duration values with the same structure as the one 
reported above for $\mathrm{f} 0$ differences did not find a significant effect of type of lexical accent.

There are a couple of reasons why an analysis in terms of differences in $\mathrm{f0}$ within the stressed vowel may not completely capture the lexical accentual contrast. To begin with, glottalization in words with a Falling/Broken accent interferes with the calculation of $\mathrm{fo}$ min. Secondly and importantly, in words in phrase-final position a boundary tone may be partially realized within the stressed syllable, resulting in greater than expected differences between $\mathrm{f0}$ min and $\mathrm{f} 0$ max in Levelaccent words, even if the pitch is level during most of the duration of the vowel. In words with a Falling accent, a following High boundary may affect the realization of the underlying falling contour. A more detailed analysis requires the consideration of the interaction between tonal accent and boundary tone, which we undertake in the next subsections. Since the number of tokens in each condition is relatively small, the description we provide is qualitative.

\subsection{Intonation-phrase-medial position}

In phrase-medial position, word accents do not compete for their realization with boundary tones. Thus, we expect lexical accents to be realized faithfully in this position. In our data, phrase-medial Falling/Broken accents are always realized with the expected pitch fall. The fall may be immediately preceded by a rise in somewhat emphatic pronunciation, as in Figure 3, so that the word bears an $\mathrm{LH}^{*} \mathrm{~L}$ contour.

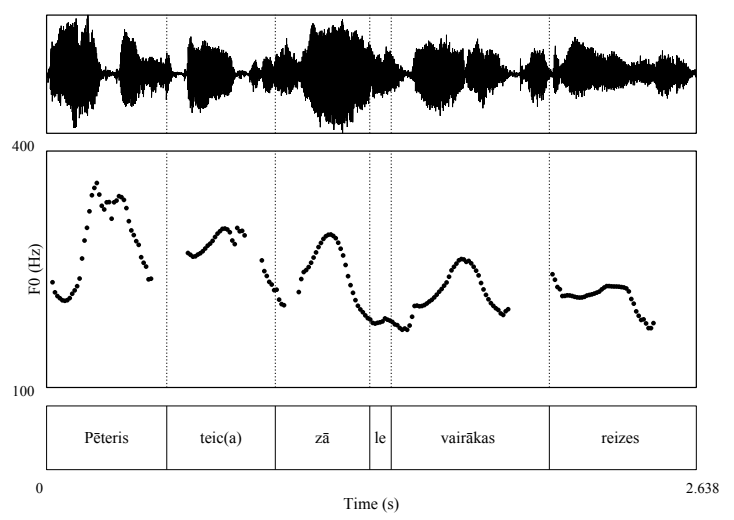

Figure 3. Pēteris teica zāle vairākas reizes 'Peter said grass (Falling/Broken accent) several times'. L1f

Words with a Level accent in phrase-medial position are generally realized with a sustained tone, whose relative pitch varies.

\subsection{Phrase-final before a High boundary (H\%, HL\%)}

In several contexts in our materials, the target word is often found before a High boundary tone: (9) Neutral yes-no question, (11) Surprise/incredulity yes-no question, (12) Suggestion yes-no question, (14) Continuation, and (15) Whquestion, although Low boundaries may also be employed in these contexts. Within the category of High boundaries examined in this section we include both final rises $(\mathrm{H} \%)$ and rising-falling boundaries (HL\%), where the pitch falls at the very end after a steep rise.

When the target word is found at the end of the phrase, a following $\mathrm{H} \%$ boundary alters the realization of the Falling/Broken accent. The final rise is apparently incompatible with an immediately preceding word accent fall. The Level accent, in turn, appears to create some incompatibility with both $\mathrm{H} \%$ and $\mathrm{L} \%$ boundary tones, especially if the stressed syllable is word final, as in our example stāvs [stã:vs] 'floor'.

In Figure 4 we show realizations of stā vs [stà:vs] (Falling) 'steep' stāvs [stã:vs] (Level) 'floor' side by side. These contours have been extracted from sentences expressing surprise/incredulity question. Both examples show a final rise that starts towards the end of the vowel. In addition to an observable difference in duration, we may note that the pitch remains relatively flat until the final boundary-induced rise in the Level accent word on the right (both examples produced by L1f). A perception experiment would be needed to determine how accurately the two accent classes can be differentiated by native speakers in this intonational context.

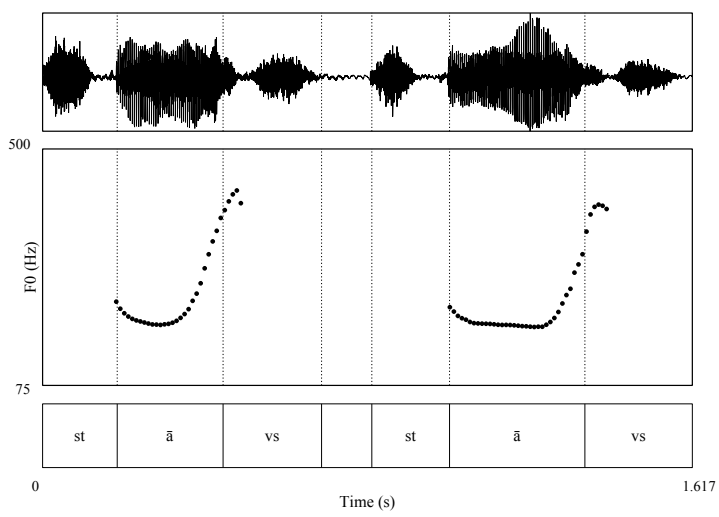

Figure 4. Surprise/incredulity question. (Vai Pēteris teica) stāovs [stã:vs]/[stà:vs] '(Did P. say) floor/steep!?' Falling vs. Level accent preceding a H\% boundary tone. LIf

A total of 17 target words in the Falling/Broken accent class were produced phrase-finally together with a final $\mathrm{H} \%$ or $\mathrm{HL} \%$ boundary, all of them in one of the three discourse contexts that involve yes-no questions. In general, the realization is as in Figure 5, also when the final syllable is unstressed ( $z \bar{a} l e$ 'grass') Some of these tokens show glottalization of the stressed vowel, which may allow for lexical identification even in the absence of an accentual fo fall.

21 target words with Level accent were produced phrasefinally together with a final $\mathrm{H} \%$ or $\mathrm{HL} \%$ boundary. 19 of these cases were realized with f0 contours as in the right-hand example in Figure 5, i.e. relatively low flat pitch with a steep rise starting towards the end of the stressed vowel or in the following consonant. The remaining 2 examples, both monosyllabic targets and by the same speaker, were produced with earlier beginning of the rise, with the consequence that the Level tone was not realized as such. This raises questions regarding the phonological nature of the Level accent.

For the Level accent, the same strategy as in Figure 4 is also found before a sentence-internal boundary rise as in the production of the sentence Pêteris teica zāle vairākas reizes 'Peter said hall several times' by L1f in Figure 5, where the speaker has introduced a sentence-internal rise (which is less steep than a question rise), which breaks up the utterance into two intonation phrases. 


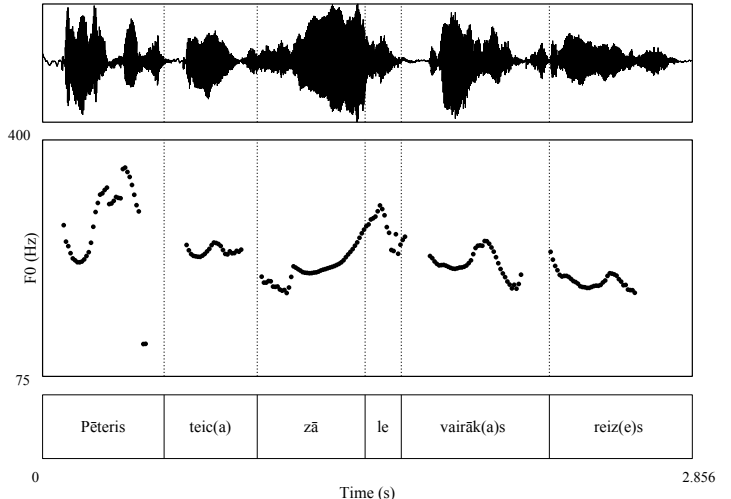

Figure 5. Pēteris teica zāle vairākas reizes 'Peter said hall (Level accent) several times'. LIf

\subsection{Phrase-final before a Low boundary (L\%)}

Final L\% boundaries were almost always produced (with the exceptions discussed in the next subsection) in the following contexts where the target word is sentence-final: (2) Contrastive focus, (4) Broad focus, (5) Narrow focus, (8) Postfocus, and (9) Command. As already mentioned, some interrogative sentences were also realized with a final fall, especially wh-questions and suggestions. Immediately preceding a L\% boundary, the Falling/Broken accent was systematically produced as a falling contour $\mathrm{H}^{*} \mathrm{~L}$ by all four speakers, hence harmonically. The Level accent was realized as a mostly flat contour over the stressed vowel in this intonational context, but its height is variable. In order for the sustained tone to be realized as such, the final fall is left unrealized with some frequency, as discussed in 3.5 .

\subsection{Final Level accent with a sustained tone (\%)}

In some contexts where a final fall would be expected, we find instead a level ending, continuing the tone height of the preceding Level accent. An example is shown in Figure 6.

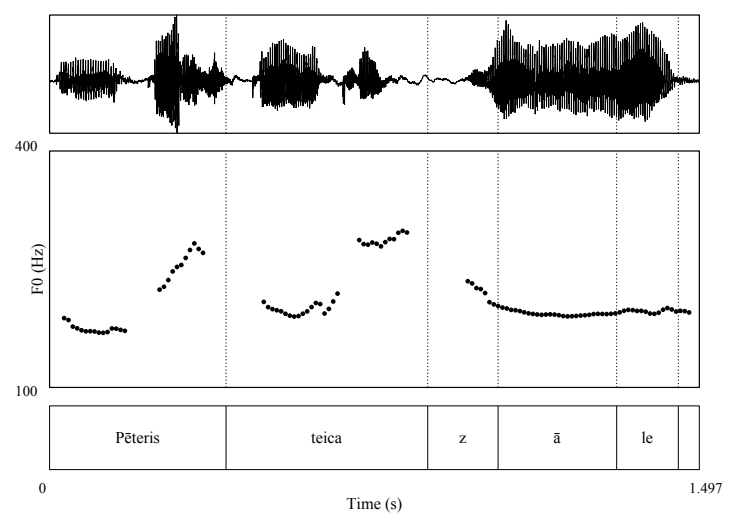

Figure 6. Pēteris teica zāle (Level accent) 'P. said hall'. Example of final sustained tone (\% boundary). LIf

Phonologically this contour may be analyzed as presenting a \% boundary, without a specification for tonal value. A phonological alternative would be to represent the Level accent as unspecified $\mathrm{T}^{*}$ over both morae.

\section{Summary and discussion}

We found two main instances of divergence from the canonical word accent realizations in phrase-medial position (See Table 2 ). We hold the incompatibility with a boundary tone responsible for this. Firstly, before a $\mathrm{H} \%$ boundary, words with Falling/Broken accent may be produced with a rising contour, instead of a falling contour, or with only a very slight fall before the final rise. In this case the word accent specification is sacrificed, so that the difference between the two accents in this contexts is (quasi-)neutralized, although duration and glottalization could still be used as cues to convey the lexical contrast. Secondly, in contexts where a final fall may be expected, a phrase-final Level accent word may trigger instead a sustained final contour; that is the $\mathrm{L} \%$ boundary is left unrealized.

A possibility would be to postulate a difference in the lexical status of the two accentual tones, so that only a level tone is lexically specified, and hence more faithfully reproduced across context than the falling tone, which could be analyzed as the default accentuation. This would account for the behavioral asymmetry between the tones that we have found. However, Kariņš proposes the reverse analysis, a lexical L in the Falling accent [2]. At any rate, the asymmetry itself invites an analysis of the contrast as privative.

If a $\mathrm{L} \%$ boundary tone is indeed absent following some instances of Level accent words, that may challenge Gussenhoven's claim that boundary tones are generally prioritized over and above preceding tones (whatever their lexical status) [13]. Alternatively, one could consider the boundary tone as preserved or merged with the preceding accentual Level tone. While the canonical realization of the Level tone is $\mathrm{H}$ (in medial position), there are contexts where it is realized as $\mathrm{M}$ or $\mathrm{L}$. The most constant feature of the Level accent is its property of being level or flat, and maybe the instances of sustained final Level accent should be analyzed as tonal merger.

\section{Conclusions}

We provisionally conclude that in Latvian there are asymmetries in the resolutions of potential conflicts between boundary tones and word accents: $\mathrm{H} \%$ is prioritized and forces dissimilatory change in both the Falling/Broken and Level accents. L\% will either merge (invisibly in $\mathrm{H}^{*} \mathrm{LL} \%$ ) or assimilate the Level tone.

We have pointed out contexts where the contrast in lexical tonal contour is potentially neutralized. A follow-up perception study is needed to further investigate this issue.

Comparison with other languages with similar prosodic properties would be of great theoretical and typological importance. Tonal conflicts of the type presented here have been described for Central Franconian dialects [14], where a tonal contrast realized under conditions that are similar to Latvian (long sonorous syllables) interacts with a rich set of intonational options, much as in the surrounding standard varieties of Dutch.

\section{Acknowledgements}

We are grateful to our Latvian speakers for their participation. 


\section{References}

[1] A. K. Karinš̌, "Lexical tone and stress in Latvian," in Berkeley Linguistics Society 23, 1997, pp. 186-197.

[2] D. Prauliňš. Latvian: An essential grammar. London: Routledge, 2012.

[3] J. I. Hualde and T. Riad, "Word accent and intonation in Baltic" in N. Campbell, D. Gibbon, and D. Hirst (eds.) Speech Prosody 7 May 20-23, Dublin, Ireland, Proceedings, 2014, pp. 668-671.

[4] D. Bond, D. Markus, and D. Stockman, "Bilingualism and the pronunciation of Latvian intonations," Journal of Baltic Studies vol. 47, no. 3, 2016, pp. 399-410, 2016.

[5] G. Bruce, Swedish Word Accents in Sentence Perspective. Travaux de l'Institut de Linguistique de Lund, vol. 12. Lund: Gleerup, 1977.

[6] J. Pierrehumbert and M. Beckman, Japanese Tone Structure. Cambridge, Mass.: MIT Press, 1988.

[7] P. Boersma and D. Weenink, Praat: doing phonetics by computer,version 6.035, 2018. www.praat.org [computer program]

[8] R Core Team. R: A language and environment for statistical computing. R Foundation for Statistical Computing, Vienna Austria, 2017. https://www.R-project.org/.

[9] RStudio Team. RStudio: Integrated Development for R. RStudio, Inc., Boston, MA, 2016. http://www.rstudio.com/.

[10] H. Singmann, B. Bolker, J. Westfall and F. Aust, "afex: Analysis of Factorial Experiments". R package version 0.18-0, 2017. CRAN.R-project.org/package $=$ afexT.

[11] D. Bates, M. Maechler, B. Bolker and S. Walker, "Fitting Linear Mixed-Effects Models using lme4". Journal of Statistical Software, 67(1), 1-48, 2015.<doi:10.18637/jss.v067.i01>

[12] T. Hastie, R. Tibshirani, and J. Friedman, The Elements of Statistical Learning - Data Mining, Inference, and Prediction. New York: Springer, 2009.

[13] C. Gussenhoven, "On the privileged status of boundary tones: evidence from Japanese, French and Canonese English" in J. Good, E. Buckley and Th. Crane (eds.) Revealing structure. 2014 pp. $1-12$.

[14] C. Gussenhoven and F. v.d. Beuken, "Contrasting the high rise and the low rise intonations in a dialect with the Central Franconian tone", The Linguistic Review 29, 2012, pp. 75-107. 